\title{
EFFECT OF TWO REMINERALIZING AGENTS ON MICROHARDNESS OF INITIAL ENAMEL CARIES- LIKE LESIONS IN YOUNG PERMANENT TEETH
}

\author{
Reham H. Abdelaziz $B D S^{1}$, Ahmed A. Mohamed $P h D^{2}$, Dalia M. Talaat $P h D^{3}$
}

\begin{abstract}
INTRODUCTION: Dental caries in enamel is unique amongst diseases as enamel is both acellular and avascular. Thus, in contrast to other tissues, enamel cannot heal itself by a cellular repair mechanism. Nonetheless, it is now well established that the formation of incipient enamel caries is a reversible process where periods of progression alternates with periods of remineralization.

OBJECTIVES: The purpose of this study was to compare the effect of Nano-hydroxyapatite paste and casein phosphopeptide-amorphous calcium phosphate fluoride paste remineralizing capacity on initial enamel carious lesions of young permanent teeth.

MATERIALS AND METHODS: Sixty extracted young permanent teeth with a standardized window on enamel were immersed in a demineralizing solution for 48 hours to produce subsurface enamel lesions. They were divided into three groups according to remineralizing agents ( $\mathrm{N}=20)$ : group I: Nano-hydroxyapatite paste; group II: casein phosphopeptide-amorphous calcium phosphate fluoride paste; and group III: control (untreated). The enamel surface microhardness (SMH) was measured at baseline, after incipient enamel lesion formation and after treatment.
\end{abstract}

RESULTS: The mean surface microhardness (201.46) was found to be higher in teeth treated with Nano-hydroxyapatite paste than mean surface microhardness (195.61) in those treated with casein phosphopeptide-amorphous calcium phosphate fluoride paste. However, this difference was not statistically significant $\mathrm{P}=0.26$.

CONCLUSIONS: Both Nano-hydroxyapatite paste and casein phosphopeptide-amorphous calcium phosphate fluoride paste were effective for remineralization of early caries-like lesions of young permanent teeth.

KEYWORDS: Nano-hydroxyapatite, casein phosphopeptide-amorphous calcium phosphate fluoride, young permanent teeth.

1- B.D.S. Faculty of Dentistry Alexandria University

2- Professor of Pediatric and Dental Public Health Department

3- Assistant Professor of Pediatric and Dental Public Health Department

Corresponding author:

E-mail:reham_hassan_85@yahoo.com

\section{INTRODUCTION}

Dental caries in enamel is unique amongst diseases as enamel is both a cellular and a vascular. Thus, it cannot heal itself by a cellular repair mechanism in contrast to other tissues. Nonetheless, it is now well known that the formation of incipient enamel lesion is a reversible process where there is alternation between periods of progression and periods of remineralization leading to repair of the lesion (1).

It is known that the use of fluoride is considered an effective method for controlling and reducing enamel demineralization in both the primary and permanent dentitions by formation of a calcium fluoride (CaF2)-like layer on the demineralized surface $(2,3)$. Topical fluoride has been extensively used to treat and prevent incipient enamel caries lesions due to their high fluoride concentration and adhesion capacity to tooth enamel (4-8). On the other hand, the dental fluorosis resulting from excessive ingestion of fluoride has caused a shift toward new tooth re-mineralization technologies, including compounds with the additional or synergistic effects of fluoride to enhance the remineralization process and improve the mechanical properties of the demineralized surface, such as casein phosphopeptide amorphous calcium phosphate (CPP-ACP) (9) and nanohydroxyapatite (Nano-HAP) $(10,11)$.

Casein phosphopeptides have the ability to stabilize calcium and phosphate ions in the form of amorphous calcium phosphate in a metastable solution. CPP-ACP complex incorporates into dental plaque, where it acts as a reservoir of calcium and phosphate ions and maintains a supersaturation state in plaque fluid, thus facilitating remineralization (12). There are two types of phosphopeptide-based dental products: CPP-ACP in paste or mousse form and casein phosphopeptide amorphous calcium phosphate fluoride (CPP-ACPF) product (13). A number of reports have proved the efficacy of the CPPACP technology in inhibiting demineralization and enhancing remineralization of enamel and dentin in vivo and in vitro (14-20).

However, De Carvalho et al (21) stated that CPP-ACP paste with fluoride did not show any additional protection on artificial early enamel caries development on permanent teeth.

With the development of nanotechnology, a major impact on materials science has been noted. In this century, the production of materials with nanostructures has gained great attention for adsorption, catalytic, biomaterials and optical applications (22).

Nano-HAP is one of the most biocompatible and bioactive agents. The nano crystals of phosphate are smaller than $100 \mathrm{~nm}$, improving the bioactivity of the agent due to the increase in superficial area of hydroxyapatite nano particles. Thus the innovation of incorporating the calcium and phosphate ions, as nanohydroxyapatite crystals, with 9,000 ppm of fluoride may 
improve the surface hardness of the demineralized enamel and promoting remineralization (21).

De Carvalho et al (21) evaluated the remineralization effects of Nano-hydroxyapatite paste on artificial early enamel lesions of permanent teeth. They concluded that Nano-hydroxyapatite paste was effective in remineralizing the initial enamel caries lesions. Moreover, several studies have shown that nano-hydroxyapatite had the potential to remineralize artificial carious lesions following addition to toothpastes and mouthwashes (23-25).

Limited researches investigated the effect of NanoHAP paste on initial enamel carious lesions. That is why this study was designated to compare the remineralizing effect of Nano-HAP paste and CPP-ACPF on initial enamel carious lesions in young permanent teeth using microhardness test. The null hypothesis tested was that there was no difference among the effects of the two remineralizing agents on enamel microhardness.

\section{MATERIALS AND METHODS}

The Scientific Research Ethical Committee, Faculty of Dentistry, Alexandria University, Alexandria, Egypt, approved this study. Calculation of sample size was done using SPSS software, version 21.0. Armonk, NY: IBM Corp (26). Significance level was set to 0.05, and maximum $\beta$ accepted was up to 20 percent, with a minimum power of 80 percent.

The sample consisted of 60 freshly extracted young permanent teeth extracted for orthodontic purposes for microhardness evaluation. Teeth were collected from the outpatient clinic of the Faculty of Dentistry, Alexandria University and private dental Orthodontic clinics in Alexandria Governorate. Teeth free of caries, cracks, and developmental defects were included in the study.

\section{Materials:}

1-Calcium nanophosphate paste (Desensibilize Nano P, FGM Produtos Odontolgicos, Joinville, Brazil) which is Calcium nanophosphate organized in crystalline form of hydroxyapatite, potassium nitrate, water, surfactant, tensoactive, flavor, 9000 ppm sodium fluoride (21).

2-CPP-ACPF (GC MI Paste Plus, GC America Inc., Alsip, Ill., USA), which is a water-based, sugar-free cream containing Recaldent (milk derived with lactose content less than 0.01 percent) with fluoride, were used in this study (27).

3-The demineralizing solution (artificial caries solution) consisted of $2.2 \mathrm{mM}$ calcium chloride, $2.2 \mathrm{mM}$ potassium dihydrogen phosphate, $0.05 \mathrm{M}$ acetic acid, and $1 \mathrm{M}$ potassium hydroxide (KOH) to maintain a $\mathrm{pH}$ of 4.4 (28).

4-The artificial saliva was prepared by mixing $500 \mathrm{ml}$ distilled water, $20 \mathrm{~g}$ potassium chloride, $0.843 \mathrm{~g}$ sodium chloride, $0.051 \mathrm{~g}$ magnesium chloride, carboxymethyl cellulos e, $20 \mathrm{ml}$ tricalcium phosphate, and $0.05 \mathrm{M}$ sodium hydroxide to maintain a pH of 6.8 (29). The artificial saliva was renewed daily through the whole study period.

\section{5-Distilled water.}

\section{Method:}

All teeth were thoroughly cleaned using fluoride free pumice and were stored in saline solution until required for use. Roots were removed at the cement-enamel junction with a water-cooled diamond saw of a precision sectioning machine. Specimens were embedded in acrylic resin with their buccal surface facing upwards. Every tooth specimen was coated with acid-proof nail varnish, exposing only a small window in cervical third of buccal surface of enamel (4 $\times 4 \mathrm{~mm}$ ) which were exposed to the demineralizing solution to produce caries-like lesion. The exposed window was standardized in all the specimens. Before any cariogenic challenge, all specimens were assessed for enamel surface microhardness (SMH) using Digital Display Vickers Micro hardness Tester (initial base line assessment). This baseline evaluation was done, so that the effect of Nano-HAP paste and the CPP-ACPF paste, on the enamel specimens, could be verified. (21)

\section{Demineralization phase (30)}

All teeth included in the study were immersed in a demineralizing solution $(10 \mathrm{ml})$ for each specimen for 48 hours to produce subsurface enamel lesions (white spot lesion without cavitation). Specimens were rinsed with distilled water and stored in artificial saliva.

After initial caries formation, post lesion microhardness test was conducted with the same static load and time applied for obtaining the baseline measurements (second assessment).

\section{Remineralization phase (21)}

The 60 teeth were divided into three groups according to remineralizing agents $(\mathrm{N}=20)$ : Group I: Nanohydroxyapatite paste. Specimens of this group were treated with Nano-HAP once daily for 5 minutes for 7 days. Nano-HAP paste was applied with a microbrush with friction for 10 seconds. After this, the paste was kept in contact with the enamel for five minutes and removed with distilled water then specimens were stored in artificial saliva. Group II: casein phosphopeptide-amorphous calcium phosphate fluoride paste. Specimens of this group were treated with CPP-ACPF once daily for 5 minutes for 7 days. CPP-ACPF paste was applied with cotton tip and maintained in contact with enamel for five minutes and removed with distilled water then specimens were stored in artificial saliva. Group III: control (untreated), specimens of this group were stored in artificial saliva.

The post-treatment microhardness test was conducted with the same static load and time applied for baseline and post-lesion measurements (Final assessment).

All data were transferred to SPSS 21.0 software (IBM, Armonk, N.Y., USA), and analyses were performed (26). The Kruskal-Wallis test was used for comparing two or more independent not-normally distributed samples of equal or different sample sizes (31). The Friedman test was used for comparing two or more dependent not-normally distributed samples. Post-hoc Pair-wise comparison when Kruskal-Wallis test or Friedman test were significant was carried out using Mann-Whitney tests. A five percent level of significance was adopted (32).

\section{RESULTS}

The result of present study showed that the SMH values of the sound enamel (baseline) were not significantly different among the experimental groups $(\mathrm{P}=0.577)$ (Table 1). After immersion in the demineralizing solution for 48 hours, The SMH had been reduced significantly in each group (post lesion) $(\mathrm{P}<0.05)$. There was no statistically significant difference among the groups $(\mathrm{P}=$ 0.740) (Table 2). Post treatment, there were significant differences among groups post treatment $(\mathrm{P}=0.02)$. By Pair-wise comparison using Mann-Whitney test there was no statistically significant difference in surface microhardness between Nano-HAP group and CPP-ACPF group $(P=0.261)$. The nano-HAP group showed the 
highest mean microhardness values (201.4 \pm 19.3$)$, followed by CPP-ACPF group (195.6 \pm 19.6$)$, and control group (181.4 \pm 26.6$)$ (Table 3).

Table (1): Descriptive statistics of the enamel surface microhardness of three groups at baseline.

\begin{tabular}{||l|l|l|l||}
\hline & $\begin{array}{l}\text { Nano- } \\
\text { hydroxyapatite } \\
\text { paste group }\end{array}$ & $\begin{array}{l}\text { Casein } \\
\text { phosphopeptide- } \\
\text { amorphous } \\
\text { calcium } \\
\text { phosphate paste } \\
\text { group }\end{array}$ & $\begin{array}{l}\text { Control } \\
\text { group }\end{array}$ \\
\hline $\begin{array}{l}\text { Mean } \pm \text { Std. } \\
\text { Deviation }\end{array}$ & $204.75 \pm 19.4$ & $207.16 \pm 18.28$ & $202.37 \pm 25.39$ \\
\hline $\begin{array}{l}\text { KS test of } \\
\text { normality }\end{array}$ & $\begin{array}{l}\mathrm{D}=0.147 \\
\mathrm{p}=0.200 \mathrm{NS}\end{array}$ & $\begin{array}{l}\mathrm{D}=0.196 \\
\mathrm{p}=0.043^{*}\end{array}$ & $\begin{array}{c}\mathrm{D}=0.191 \\
\mathrm{p}=0.054 \mathrm{NS}\end{array}$ \\
\hline $\begin{array}{l}\text { Independent- } \\
\text { Samples } \\
\text { Kruskal- } \\
\text { Wallis Test }\end{array}$ & $\mathrm{p}=0.577 \mathrm{NS}$ & & \\
\hline
\end{tabular}

KS: Kolmogorov-Smirnov

*: Statistically significant $(\mathrm{p}<0.05)$

NS: Statistically not significant $(\mathrm{p}>0.05)$

Table (2): Descriptive statistics of the enamel surface microhardness after initial caries formation by demineralizing solution

\begin{tabular}{|c|c|c|c|}
\hline & $\begin{array}{c}\text { Nano- } \\
\text { hydroxyapatite } \\
\text { paste group }\end{array}$ & $\begin{array}{c}\text { Casein } \\
\text { phosphopeptide } \\
\text {-amorphous } \\
\text { calcium } \\
\text { phosphate } \\
\text { paste group } \\
\end{array}$ & Control group \\
\hline $\begin{array}{c}\text { Mean } \pm \text { Std. } \\
\text { Deviation }\end{array}$ & $184.03 \pm 22.83$ & $187.04 \pm 21.39$ & $183.48 \pm 26.97$ \\
\hline $\begin{array}{l}\text { KS test of } \\
\text { normality }\end{array}$ & $\begin{array}{c}\mathrm{D}=0.109 \\
\mathrm{p}=0.200 \mathrm{NS}\end{array}$ & $\begin{array}{l}\mathrm{D}=0.179 \\
\mathrm{p}=0.093^{*}\end{array}$ & $\begin{array}{l}\mathrm{D}=0.208 \\
\mathrm{p}=0.023^{*}\end{array}$ \\
\hline $\begin{array}{c}\text { Independent } \\
\text {-Samples } \\
\text { Kruskal- } \\
\text { Wallis Test }\end{array}$ & & $S$ & \\
\hline
\end{tabular}

KS: Kolmogorov-Smirnov

*: Statistically significant $(\mathrm{p}<0.05)$

NS: Statistically not significant $(\mathrm{p}>0.05)$

Table (3): Descriptive statistics of the enamel surface microhardness after treatment.

\begin{tabular}{|c|c|c|c|}
\hline & $\begin{array}{l}\text { Nano- } \\
\text { hydroxyapati } \\
\text { te paste } \\
\text { group }\end{array}$ & $\begin{array}{c}\text { Casein } \\
\text { phosphopepti } \\
\text { de- } \\
\text { amorphous } \\
\text { calcium } \\
\text { phosphate } \\
\text { paste group } \\
\end{array}$ & $\begin{array}{l}\text { Control } \\
\text { group }\end{array}$ \\
\hline $\begin{array}{c}\text { Mean } \pm \text { Std.Deviat } \\
\text { ion }\end{array}$ & $201.46 \pm 19.93$ & $195.61 \pm 19.61$ & $\begin{array}{c}181.42 \pm 26 . \\
62\end{array}$ \\
\hline $\begin{array}{l}\text { KS test of } \\
\text { normality }\end{array}$ & $\begin{array}{c}D=0.149 \\
p=0.200 \mathrm{NS}\end{array}$ & $\begin{array}{l}\mathrm{D}=0.195 \\
\mathrm{p}=0.045^{*}\end{array}$ & $\begin{array}{l}\mathrm{D}=0.210 \\
\mathrm{p}=0.021^{*}\end{array}$ \\
\hline $\begin{array}{c}\text { Independent- } \\
\text { Samples } \\
\text { Kruskal-Wallis } \\
\text { Test }\end{array}$ & \multicolumn{3}{|c|}{$\mathrm{p}=0.028^{*}$} \\
\hline \multicolumn{4}{|c|}{ Pair-wise comparison } \\
\hline $\begin{array}{c}\text { Compared with } \\
\text { Control }\end{array}$ & $\mathrm{p}=0.018^{*}$ & $\mathrm{p}=0.045^{*}$ & \\
\hline $\begin{array}{l}\text { Compared with } \\
\text { Nano- } \\
\text { hydroxyapatite } \\
\text { paste group }\end{array}$ & & $\mathrm{p}=0.261 \mathrm{NS}$ & \\
\hline
\end{tabular}

KS: Kolmogorov-Smirnov

*: Statistically significant $(\mathrm{p}<0.05)$

NS: Statistically not significant $(\mathrm{p}>0.05)$

Pair-wise comparison was done using Mann-Whitney test
Regarding each test group by using friedman test, NanoHAP group, the values of post treatment phase were significantly higher than of post lesion phase $(\mathrm{P}=0.004)$. Post treatment values were still significantly lower when compared with those of baseline phase $(\mathrm{P}=0.008$; Figure $1)$. Moreover, the values of post treatment phase of CPPACPF were significantly higher than post lesion phase $(\mathrm{P}=0.005)$. The values were still significantly lower than those of baseline phase $(\mathrm{P}=0.005$; Figure 2$)$.

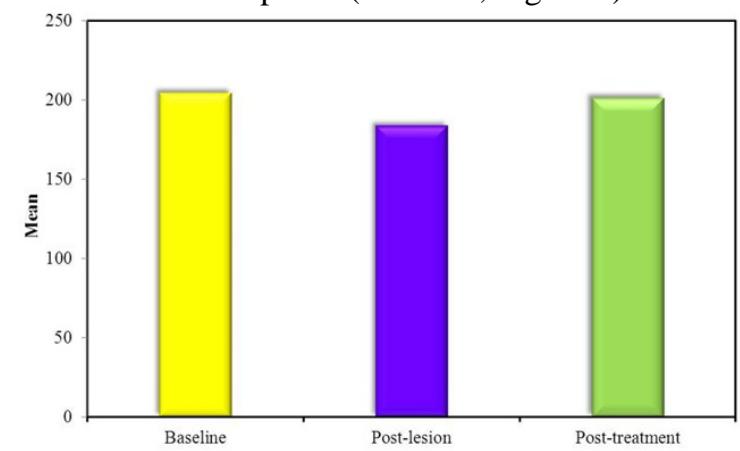

Figure 1: The mean values of Nano-hydroxyapatite group in three phases of experiment.

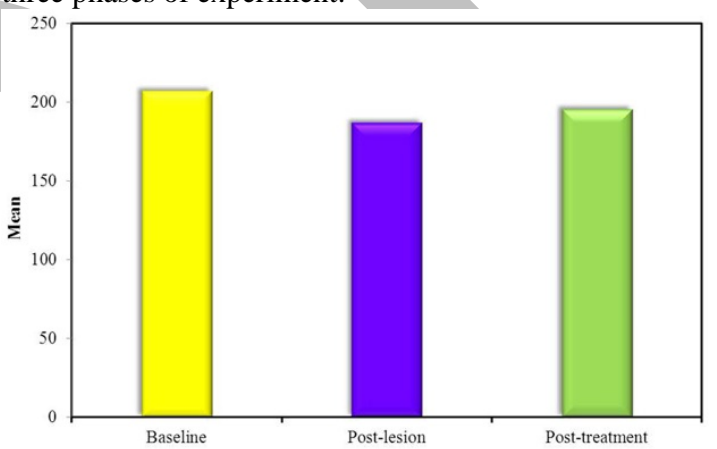

Figure 2: The mean values of Caseinphosphopeptide-amorphous calcium phosphate group in three phases of experiment.

\section{DISCUSSION}

Based on the results of the present study, the null hypothesis was not rejected. Both Nano-HAP and CPP-ACPF pastes can remineralize early enamel surface lesions.

The results showed that the demineralized enamel surfaces in all groups showed an overall significant decrease in microhardness, indicating loss of minerals, as all teeth in all groups were subjected to the same demineralizing solution, for the same period of time for standardization purpose.

After application of the remineralizing agents there was a statistical significant difference in enamel $\mathrm{SMH}$ in each group when compared with the data obtained after demineralization. Both test groups showed a significant increase in the microhardness, which indicate remineralization. The changes of microhardness in CPPACPF group were in agreement with the results of Srinivasan et al (33) and El-Zayate (34) who showed that both CPP-ACP and CPP-ACP with $900 \mathrm{ppm}$ fluoride significantly remineralized softened enamel, with greater remineralization potential of CPP-ACPF than CPP-ACP.

Furthermore, Talaat et al (35) evaluated the effect of acid on enamel subsurface lesions that were previously treated with CPP-ACPF and found that CPP-ACPF was able to remineralize the enamel subsurface lesions, due to first demineralization, and to protect them against further acid attack.

Regarding Nano-HAP group, the changes in microhardness were supported by the work of Huang et al 
(36) and Haghgoo et al (37) who evaluated its effect for remineralization of incipient carious lesions and they found that Nano-HAP greatly enhanced remineralization and increased tooth microhardness.

Moreover, by comparing the two test groups post treatment, Nano-HAP group showed better mean microhardness value compared to CPP-ACPF group with statistical insignificant difference. This result was supported by the result of De carvalho et al (38).

However, this insignificant result concerning the comparison between the two groups was inconsistent with another study conducted by De carvalho et al (21). They stated that after the cariogenic challenge, the nano-HAP group showed significantly higher microhardness values while the CPP-ACPF group showed no increase in surface microhardness. This result could be due to the fact that De carvalho conducted their latter study on extracted third molars and used different study design. Additionally in the present study, the post treatment microhardness values of both test groups were similar to those of baseline values. Although, there was a statistical significant difference. This revealed that nano-HAP and CPP-ACPF pastes are used for prevention not for treatment.

It is important to clarify that Nano-HAP showed the largest increase in microhardness values. This may be due to the application method of this paste (10 sec. of friction) and the calcium nanophosphate crystals may have penetrated more deeply into the defects of the carious enamel, forming a "reservoir-like" deposit of calcium and phosphate ions. The reservoir-like deposit could make these ions available during a subsequent cariogenic challenge and help maintain a state of supersaturation with enamel minerals (11). Furthermore, the fluoride concentration in the nano-HAP paste is 10 times higher (9000 ppm) than that of the CPP-ACP paste (900 ppm). This higher concentration may affect the remineralization process (33).

\section{CONCLUSION}

Based on this study's results, the following conclusions can be made:

- Nano-hydroxyapatite paste and Casein phosphopeptide amorphous calcium phosphate fluoride paste were effective in rehardening the initial enamel caries lesions caused by demineralizing solution in young permanent teeth.

- Nano-hydroxyapatite paste showed better mean microhardness values compared to Casein phosphopeptide amorphous calcium phosphate fluoride paste with statistical insignificant difference.

- The two remineralizing agents can be used for prevention of early enamel carious lesion.

\section{CONFLICT OF INTEREST}

The authors declare that they have no conflicts of interest.

\section{REFERENCES}

1. Zero DT. Dental caries process Dent. Clin North Am. 1999; 43: 635-64.

2. Tenuta LMA, Cury JA. Fluoride: its role in dentistry. Braz Oral Res. 2010; 24: 9-17.

3. Ten Cate JM. Current concepts on the theories of the mechanism of action of fluoride. Acta Odontol Scand. 1999; 57: 325-9.
4. Minah G, Lin C, Coors S, Rambob I, Tinanoff N, Grossman LK. Evaluation of an early childhood caries prevention program at an urban pediatric clinic. Pediatr Dent. 2008; 30: 499-504.

5. O'Keefe E. Fluoride varnish may be effective in preschoolers. Evid Based Dent. 2011; 12: 41-2.

6. Azarpazhooh A, Main PA. Fluoride varnish in the prevention of dental caries in children and adolescents: a systematic review. J Can Dent Assoc. 2008; 74: 73-9.

7. Almeida MQ, Costa OX, Ferreira JM, Menezes VA, Leal RB, Sampaio FC. Therapeutic potential of Brazilian fluoride varnishes: an in vivo study. Braz Dent J. 2011; 22: 193-7.

8. de Amorim RG, Leal SC, Bezerra AC, de Amorim FP, de Toledo OA. Association of chlorhexidine and fluoride for plaque control and white spot lesion remineralization in primary dentition. Int J Paediatr Dent. 2008; 18: 446-51.

9. Yengopal V, Mickenautsch S. Caries preventive effect of casein phosphopeptide-amorphous calcium phosphate (CPP-ACP): a meta-analysis. Acta Odontol Scand. 2009; 67: 321-32.

10. Huang SB, Gao SS, Cheng L, Yu HY. Combined effects of nano-hydroxyapatite and Gallachinensis on remineralization of initial enamel lesion in vitro. J Dent. 2010; 38: 811-9.

11. Huang S, Gao S, Cheng L, Yu H. Remineralization potential of nano-hydroxyapatite on initial enamel lesions: an in vitro study. Caries Res. 2011; 45: 460-68.

12. Cross KJ, Huq NL, Palamara JE, Perich JW, Reynolds EC. Physicochemical characterization of casein phosphopeptide-amorphous calcium phosphate nanocomplexes. J Biol Chem. 2005; 280:15362-15369.

13. Llena C, Forner L, Baca P. Anticariogenicity of casein phosphopeptide amorphous calcium phos- phate: a review of literature. J Contemp Dent Pract. 2009; 10: 1-9.

14. Yengopal V, Mickenautsch S. Caries preventive effect of casein phosphopeptide-amorphous calcium phosphate (CPP-ACP): a meta-analysis. Acta Odontol Scand. 2009; 67: 321-32.

15. Reynolds EC. Remineralization of enamel subsurface lesions by casein phosphopeptide-stabilized calcium phosphate solutions. J Dent Res. 1997; 76: 1587-95.

16. Lata S, Varghese NO, Varughese JM. Remineralization potential of fluoride and amorphous calcium phosphatecasein phosphopeptide on enamel lesions: an in vitro comparative evaluation. J Conserv Dent. 2010; 13: 42-6.

17. RehderNeto FC, Maeda FA, Turssi CP, Serra MC. Potential agents to control enamel caries-like lesions. J Dent. 2009; 37: 786-90.

18. Zhang Q, Zou J, Yang R, Zhou X. Remineralization effects of casein phosphopeptide-amorphous calcium phosphate creme on artificial early enamel lesions of primary teeth. Int J Paediatr Dent. 2011; 21: 374-81.

19. Rollings S, Greene L, Borrie F, Lamont T. Small trial finds beneficial effect for MI Paste in preventing white spot lesions during orthodontic treatment. Evid Based Dent. 2012; 13: 117-8.

20. Baroni C, Marchionni S, Bazzocchi MG, Cadenaro M, Nucci C, Manton DJ. A SEM and non-contact surface white light profilometry in vivo study of the effect of a crème containing CPP-ACP and fluoride on young etched enamel. Scanning. 2014; 36: 270-7.

21. De Carvalho FG, Vieira BR, Santos RL, Carlo HL, Lopes PQ, De Lima B. In Vitro Effects of Nano- 
Hydroxyapatite Paste on Initial Enamel Carious Lesions. Pediatr Dent. 2014; 36: 85-9.

22. Ramli RA, Adnan R, Bakar MA, Masudi SM. Synthesis and characterization of pure nanoporous hydroxyapatite. J Phys Sci. 2011; 22: 25-37.

23. Yamagishi K, Onuma K, Suzuki T, Okada F, Tagami J, Otsuki M, et al. A synthetic enamel for rapid tooth repair. Nature. 2005; 24: 433-819.

24. Kim MY, Kwon HK, Choi CH, Kim BI. Combined effects of nano-hydroxyapatite and $\mathrm{NaF}$ on remineralization of early caries lesion. Key Eng Mater. 2007; 330-2, 1347-50.

25. Lu KL, Zhang JX, Meng XC, Li XY. Remineralization effect of the nano-HA toothpaste on artificial caries. Key Eng Mater. 2007; 330-2, 267-70.

26. IBM. SPSS Statistics for Windows. Version 21.0. Armonk, NY: IBM; 2012.

27. Cem G, Ebru C, Seval Ö. Remineralizing effect of different topical agents on occlusal surfaces with or without caries: an in vitro evaluation study using electrical resistance measurements.Clin Dent and Res. 2012; 36: 4-9.

28. Kumar VL, Itthagarun A, King NM. The effect of casein phosphopeptide-amorphous calcium phosphate on remineralization of artificial caries-like lesions: an in vitro study. Aust Dent J. 2008; 53: 34-40.

29. Kawai K, Heaven TJ, Retief DH. In vitro dentine fluoride uptake from three fluoride-containing composites and their acid resistance. J Dent. 1997; 25: 291-6.

30. Vieira AEM, Delbem ACB, Sassaki KT, Rodrigues E, Cury JA, Cunha RF. Fluoride dose response in $\mathrm{pH}$-cycling models using bovine enamel. Caries Res. 2005; 39: 514-20.

31. Kruskal WH, Wallis WA. Use of Ranks in One-Criterion Variance Analysis. J Am Stat Assoc. 1952; 47: 583-621.

32. Friedman M. The use of ranks to avoid the assumption of normality implicit in the analysis of variance. J Am Stat Assoc. 1937; 32: 675-701.

33. Srinivasan N, Kavitha M, Loganathan SC. Comparison of the remineralization potential of CPP-ACP and CPP-ACP with 900 ppm fluoride on eroded human enamel: An in situ study. Arch Oral Biol. 2010; 55: 541-4.

34. El Zayat A. The effect of casein phosphopeptideamorphous calcium phosphate on remineralization of caries-like lesions in primary teeth. MS thesis; Faculty of Dentistry, Alexandria University; 2012.

35. Talaat DM, Mahmoud A. Acid resistance of enamel subsurface lesions treated with casein phosphopeptide amorphous calcium phosphate fluoride. J Dent Child. 2015; 82: $70-5$.

36. Huang SB, Gao SS, Yu HY. Effect of nano-hydroxyapatite concentration on remineralization of initial enamel lesion in vitro. Biomed Mater. 2009; 4: 034104.

37. Haghgoo R, Rezvani MB, Zeinabadi MS. Comparison of nano-hydroxyapatite and sodium fluoride mouth rinse for remineralization of incipient carious lesions. J Dent. 2014; 11: 406-10.

38. De Carvalho GF, Brasil V, Filho T, Carlo H, Santos R, de Lima B. Protective effect of calcium nanophosphate and ACP-CPP agents on enamel erosin. Braz Oral Res. 2013; 27: 463-70. 